\title{
THE IMPORTANCE OF TRAINING NEED ASSESSMENT ON COMPETENCY- BASED Training OF TECHNiCAL GUIDANCE OF ENERGY AUDITOR IN CEMENT INDUSTRY
}

\author{
Sunyoto $^{1)}$, Robinson Situmorang ${ }^{2)}$, Etin Solihatin ${ }^{3)}$ \\ ${ }^{1)}$ Universitas Negeri Jakarta, Indonesia \\ E-mail: sunyoto_tp15s3@mahasiswa.unj.ac.id \\ ${ }^{2)}$ Universitas Negeri Jakarta, Indonesia \\ E-mail: robinson.situmorang@gmail.com \\ ${ }^{3)}$ Universitas Negeri Jakarta, Indonesia \\ E-mail: etin_solihatin@unj.ac.id
}

\begin{abstract}
Training needs assessment or training needs analysis is a move made prior to training and a part in the design of integrated training in order to obtain a comprehensive picture of the material, the allocation of time, and learning strategies that should be applied in conducting Technical Guidance Training of Energy Auditor. In this case, identifying training needs (Training Needs Analysis) is the second step after identify desired result (SKKNI Comply) in the development of a training model Technical Guidance of energy Auditor. Identification of training needs carried out by the training institutions in the cement industry is micro case, namely the identification process to find out the "gap" the competence that is owned by the labor force with the requirements of the position. Program Technical Guidance Training of Energy Auditor prepared based on Standard of Competence Workplace of Indonesia (SKKNI) in the field audits of energy audit as desired field workforce performance which is refer to Human Performace Technology (HPT) model.
\end{abstract}

Keywords: Training Needs Assessment and Analysis; Competency Gap; Training Based Competency; SKKNI

\section{INTRODUCTION}

Training Needs Assessment (TNA) or training needs analysis is a step prior to training and a part in the design of integrated training in order to obtain a comprehensive training material, the allocation of time, and learning strategies that should be applied in the organization of training in order to be useful for training participants. From this analysis will note any relevant training for an organization at present and also in the future. The Organization cannot determine the training for granted without first analyzing the needs and goals of what you want to accomplish. Needs assessment is a road map to achieve the organizational goal(s).

Competency-based training (CBT) for experienced employees of the cement factory as well as employees on probation are a company's strategic internal because it is a central function in supporting the ability of the company's effectiveness in achieving the objectives and the development of company's business in the future. The existence of the employees which has high competence and up to date is the strong capital for companies in carrying out basic tasks and functions effectively. The improvement of the competence of human resources in the industry is the responsibility of the Government cq Ministry of Industry and Ministry of Manpower and Transmigration. It is due to of the main functions is to build the human resource competency in cement industry is to increase the knowledge, skills, and attitudes to be able to perform the duties of the position professionally (PP 101 year 2000). In order that the functions of the human resources competency building effective, governments need to prepare good infrastructure (hardware) or a program (software).

The training program aims to develop human resource competence through Competency-based Training (CBT). The CBT needs the structure of curriculum and syllabus- 
based competencies which are often termed as competencybased Curriculum. By using this approach, the Training unit of the CBT is responsible of Ministry of Industry and Ministry of Manpower and Transmigration which will be able to ensure competences required by the company/units under it, how to measure the achievement of competencies trained, and what indicators are applied to find out if the employees have mastered a given competency. Competencybased training curriculum design means using competency profiles as a basis for conducting needs analysis training. The result is a set success profile of each unit's next used to determine the syllabus and curriculum of the training which will be arranged. In this article, the author tried to elaborate on things related to the organization of education and training with further discus on instructional design training.

In the field of human resources, many definitions and models for the assessment of needs, each comes with a small difference. For researchers and practitioners, the needs assessment is the process of investigation with the aim of linking performance problems or opportunities for improvement organizational performance to specific interventions on human performance. Needs assessment thus also involves the process of distinguishing the components performance issues that should be addressed by training and that should be addressed by the intervention other than training. Nancy O. Berger in his book "Human Resources and their development, vol. 1 mentions:" In simple terms, the needs assessment is a systematic process for identifying gaps in performance and uncovering the causes of those gaps, or for identifying future performance needs. This interpretation is based on the concept of performance discrepancies or gaps--the difference between a current level (what is) and a desired level (what should be) ".

Notions that are sometimes used synonymously includes needs analysis, front-end analysis and performance analysis. However, each of these terms has also been used to describe the process that is clearly different, depending on the author. Some professionals recommend that the difference between the terms "needs assessment" and "needs analysis". In this case, the needs assessment often refers to a broader investigation of the performance of the Organization, while the needs analysis pointed to a more narrowly focused analysis, such as the classification of a particular job. In this article the term "needs assessment" will be used to appoint general or more specific types of analysis. Rossett (2009: 31) said: "Training needs assessment study is to design and develop instructional and informational programs and materials, after the performance analysis has determined that training or informational materials are indeed appropriate". Training needs can be note if the imbalances occur between conditions (knowledge, skills and behaviors) that there are actually with the expected objectives are created in an organization. Educational needs or training needs is a measurable gap between current results and results that are desired or required. Not all gaps or needs to have the same importance to immediately met. Then between the selected interests needs to be filled sometimes problems occur or selected gap.
Analysis of training needs according to Rosset and Arwady mentioned that Training Needs Assessment (TNA) is a term used in the analysis to understand the problems of performance or problems relating to the application of technology recently. Training needs analysis holds an important role in any training program, because of this analysis will note any relevant training for an organization at present and also in the future, which means in the stage analysis These training needs can be identified what type of training needed by employees in establishing obligations. The function of training need assessment: (1) Gather information about skill, knowledge and feeling. (2) Gather information about job content and job context. (3) Defining performance standards and actual performance in operational details. (4) Involve all stakeholders and form support. (5) Give your data for the purposes of planning.

Suparman (2014:132) posited in the first step of the MPI namely instructional needs and identify the writing Goals Public Instructional (TIU). Identify instructional needs (Training Needs Assessment), intended to identify the existence of a gap (gap) between the employee's current performance and the expected performance. In the development of competency-based training model Technical Guidance Training first phase of Energy Auditors, the gap between the performance of the auditor's certificate of competence before getting energy with the expected performance (identify desired result: SKKNI comply). This competence certificates stating that the auditor has complied with the provisions of the energy legislation.

There are several approaches in conducting a TNA, among the most popular are:

1. Macro: TNA which is based on the needs of organizations/companies in General, so that his TNA results apply to everyone in it. Therefore, it is often called the Organization-Based Analysis. TNA Macro can use data sources include: (a) the vision, mission, strategic objective and the target company; (b) Economic and financial state of the company; (c) cultural change; (d) changes in technology; (e) corporate themes, such as cost reduction, quality improvement, etc.

2. Micro: TNA which is based on the needs of a particular group which consists of 2, i.e.: (a) Task-Based Analysis, whose main focus is whether the standard of skills required in a job already possessed by the holder of the Office or not;. (b) the Person-Based Analysis that his main focus is whether employees can already do the job according to demands or not. TNA Micro can use data sources include: (1) Job Description; (2) Performance standard; (3) Performance evaluation; (4) Observation of work; (5) Interview; (6) Questionnaire; (7) Checklist.

A few researchers distinguish between training needs analysis and training needs assessment. The need for training occurs when there is a gap at the level of performance, behavior or attitude and this gap hindering the success of the company. When the level of morale and motivation among the employee's motivation declining, and hence there is a 
need to update knowledge of workforce. Training needs analysis is the process of finding out the gap between current performance standards and performance standards that are required, these. Like when you go from point $\mathrm{A}$ to point $\mathrm{B}$, we are sure what it is and what it is A or B. Training needs analysis allows the Manager to identify performance gaps and address them with appropriate training programs. Training needs analysis is the analysis of top training, learning and development needs of employees in the company. This analysis includes the skills, knowledge and of employees in the company and how to develop it, both to give the company's strategic objectives as well as to support employee career.

While the Training Needs Assessment is a process that allows us to determine the types of knowledge, skills, ability of volunteer, and supervisors which can be reached by way of learning. It is used to determine the required training and identify knowledge gaps between the skills of employees in doing its job. Training Needs Assessment is the process by which we can determine the types of knowledge, skills, and abilities of employees who can be reached through learning that is meaningful. This is a way to find out the needs of employees who can be filled with training.

It can be said that the final results of the training need analysis and training need assessment will identify training needs. What's different will arise over the methodology used to reach conclusions. Training needs analysis will involve a lot of analysis of the data collected through interviews, focus group discussion, on the observations of work etc. Assessment of training needs, on the other hand will involve preparation of tests, assessment to assess the level of knowledge of the participants who then will help us determine what type of training for target groups that need and at rankings which. Watkins, Meiers and Visser's (2012) said that training needs is a tool for collecting information, make informed decisions and achieve the expected development result is resources are exceptional resource that helps to develop the training or the non-intervention training as shown in Fig. 1.

Performance problems or other opportunities begin with a need's assessment. When performing a needs assessment, we will use the needs analysis and performance analysis. The results of the needs assessment is used to determine whether it needed the intervention of non-training and/or training intervention. If necessary, the intervention training, then to do the analysis of training needs (TNA). TNA using task analysis to determine what should be trained and what not. In this situation the required assessment function are in the system for training and conducted by specialist training. How many non-intervention trainings which can be recommended? This is a display of the very top macro needs assessment that aims to make us all a little wiser about when to use the NA or may never use the acronym at all?

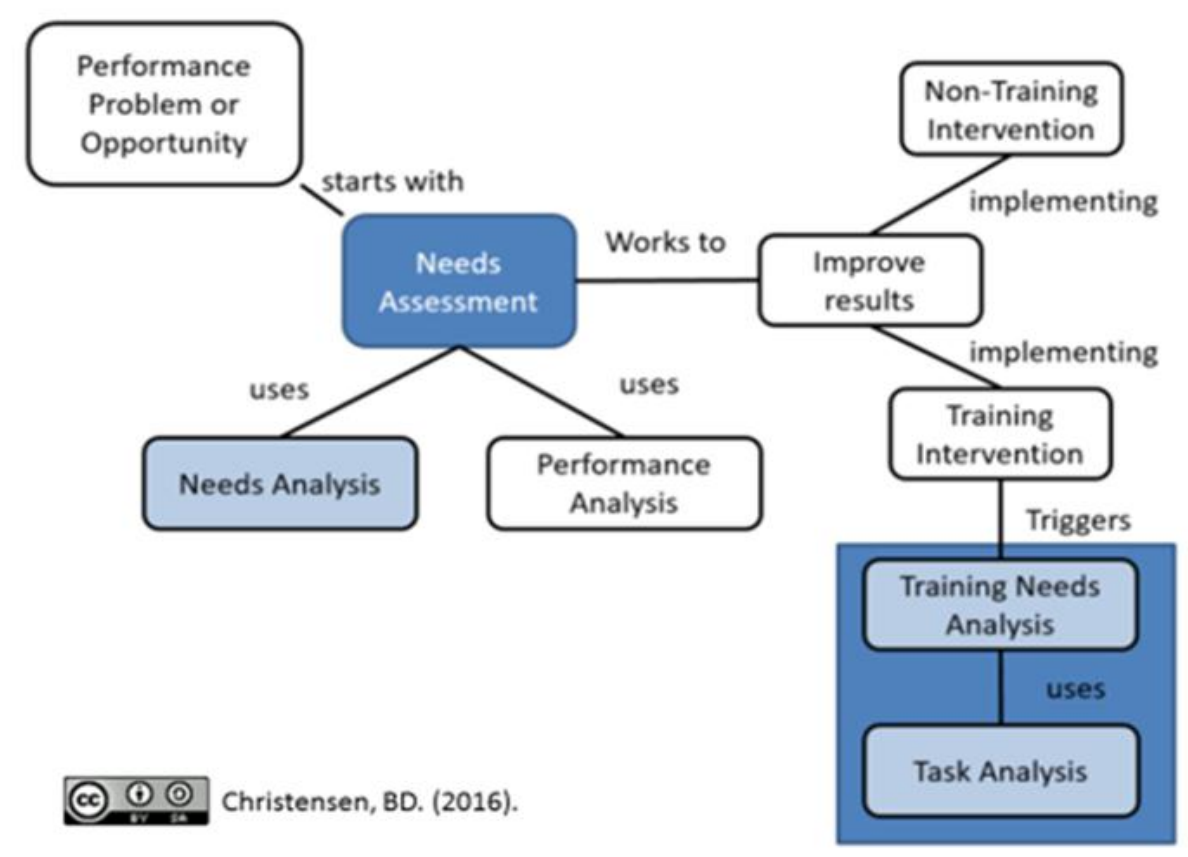

Fig. 1 Chart of training needs analysis and the task analysis

\section{Methodology}

This research aims to develop Technical Guidance Instructional model of energy Audit to get a Certification of competence of the profession in the cement industry is expected to increase the effectiveness of learning. Instructional model that will be developed in this research is the ability to solve problems in the workplace especially in the aspect of knowledge in the implementation of the activities of the energy audit. Research and Development $(\mathrm{R} \& \mathrm{D})$ is a research method that is used to produce a particular product, and test the effectiveness of these products. As expressed by Gall \& Borg that research and development in education is an industry-based model of development where research findings used to design new 
products and procedures, which are then systematically tested in field, evaluated, and enhanced to meet certain criteria, namely effectiveness and quality. According to Borg and Gall, educational research and development approaches is used to develop and validate educational product, or it can mean that the research is the development of education is a process used to develop and validate product education. The result of the research of the development of not only the development of an existing products but also to find the answers to the knowledge or practical problems. Based on the above definition, it is understood that development research is a move to develop a new product or refining existing products and effectiveness test, as well as the longitudinal nature of the gradual or can multi-years.

Furthermore, Borg and Gall described four main characteristics in research and development, namely: (1) Wadi research findings pertinent to the product to be develop, which means, doing the initial research study or to find research findings related to the product will be developed. (2) Developing the product base on these findings, that is to say, developing products based on the findings of such research. (3) Field testing it in the setting where it will eventually be used to mean, he did field test in the setting or actual situation where the products were later used. (4) Revising it to correct the deficiencies found in the field-testing stage, that is to say, did the revision to correct the weaknesses found in the stages of field test. The four main characteristics of the R\&D, giving an overview of the key features that $R \& D$ is the initial research steps related to the products that will be developed. Based on the results of research education and training products are designed and developed to test and then repaired/revised. More over Borg and Gall (1983:775) said there are 10 steps in research and development for small-scale learning (Fig. 2).

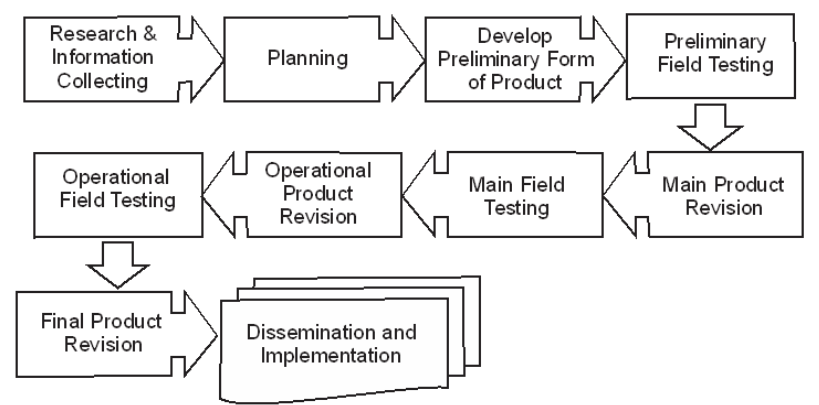

Fig. 2 The 10 stages of Research Development (R\&D) \& Borg \& Gall source: Borg \& Gall "Educational Research, An Introduction" Longman Inc. $(1983: 775)$

Referring to the methodology of the Research used in the Technical Guidance instructional model of Energy Auditor training, chart in Fig. 3 shows how the Technical Guidance of Energy Auditor training developed through the research phase, and development stage compared with Research Development model combination of Borg \& Gall and instructional model Dick \& Carey. Chart Research Development model combination of Borg \& Gall with instructional model Dick \& Carey (Fig. 2) expanded into 6 combinations of instructional model (Fig. 3). Six instructional models were added in the early stage of the research are Backward Design (1990), Human Performance Technology (1980), 4-D Model (1974), Training Need Assessment Freed Nickols (2005), with a model Training Competency-based (ILO 2013). At this stage of development used Instructional Design Dick \& Carey/MPI Model in developing a Technical Guidance training model of energy auditor (Suparman, 2014).

Preparation of Training development model of technical guidance (Technical Guidance Training) using the stages of Research Development consists of 5 main stages: (1) Identify Desired Result (SKKNI comply); (2) Competencybased training needs analysis which is the stage of research; (3) Compile instructional design; (4) Formative evaluation of the system learning; and (5) Implementation, evaluation, summative and diffusion of innovation. The latest three stages (stage 3, 4 and 5) are the stage of Development in the methodology Research \& Development (R\&D). 


\section{Research Development}

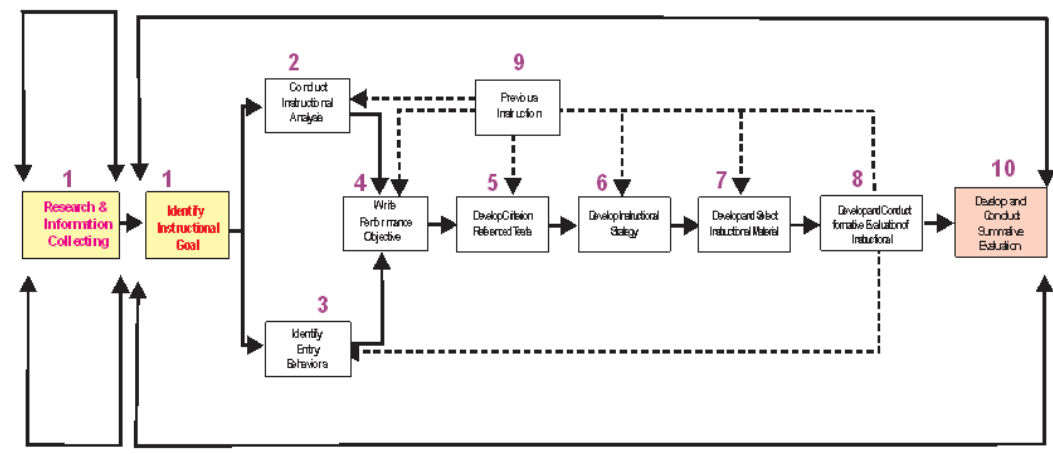

Borg\&Gill

Dick \&Carey

RESEARCH

DEVELOPMEN T

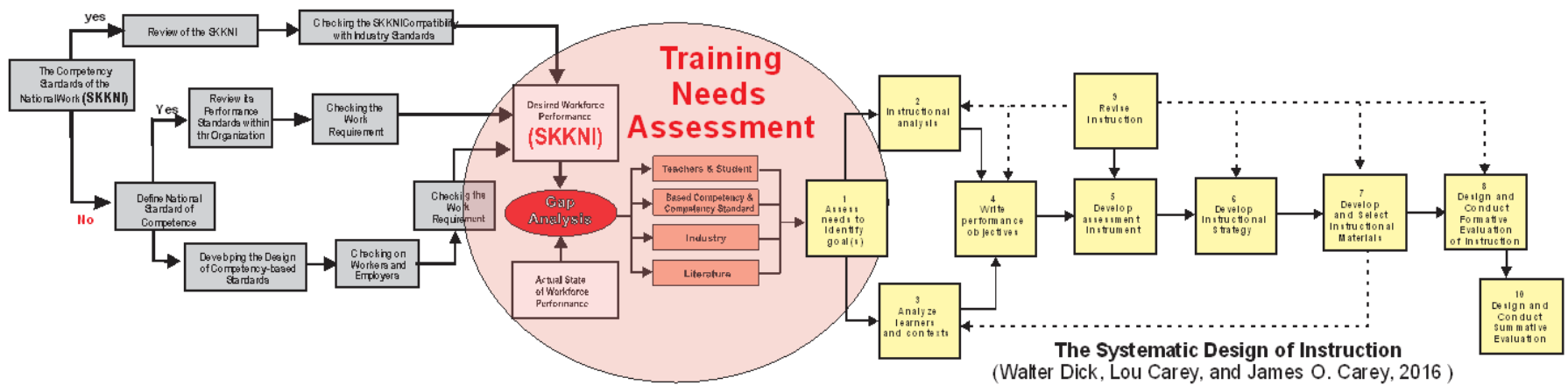

Fig. 3 Two Stages of Research Development on the Technical Guidance Model training of Energy Auditor Comparing to the Research Development on the model of combination of Borg \& Gall and Dick \& Carey

The five main stages consisted of 24 steps: (1) The development of cement industry competency map; (2) Develop Standard of Competence Workplace of Indonesia (SKKNI) for Energy Audits in the cement industry; (3) Preparation of SKKNI for Energy Audit in the cement industry; (4) Determination of SKKNI for Energy Audit in the cement industry; (5) Preparing the certification scheme for Energy Audit in the cement industry; (6) Preparation of Material Competence for the energy Audit in the cement industry; (7) Analysis of Energy Auditor competency gaps in the cement industry; (8) Competency-based training needs Analysis for the energy audit; (9) Identification of training needs and technical guidance set a goal of common instructional (SKKNI Energy Auditor); (10) Instructional analysis; (11) The identification of the behaviour and characteristics of Early Learners (certification scheme); (12) Set a goal of training Competency Cluster (Special Auditors Energy in the cement industry); (13) Write the reference benchmark test (pre-test assessment and final assessment test); (14) Strategy of technical guidance training; (15) Develop training materials technical guidance training (certification assessment material test); (16) Putting together learning, Formative Evaluation stage, (17) Stage 1 evaluation of one-one with 3 (three) experts, the Formative Evaluation; (18) Stage 2-evaluation with 3 (three) learners, Formative Evaluation; (19) Stage 3-evaluation with 3 (three) small groups of learners; (20) Stage 4-field trials with about 30 students; (21) Prototype system development technical guidance training set; (22) Implementation model of learning; (23) Summative evaluation; (24) The diffusion of innovation model technical guidance training in cement industry. A thorough overview of the major phases of the instructional model 5 and 24 step the preparation of model on the development of technical guidance training of energy auditor training can be seen in Fig. 4. 


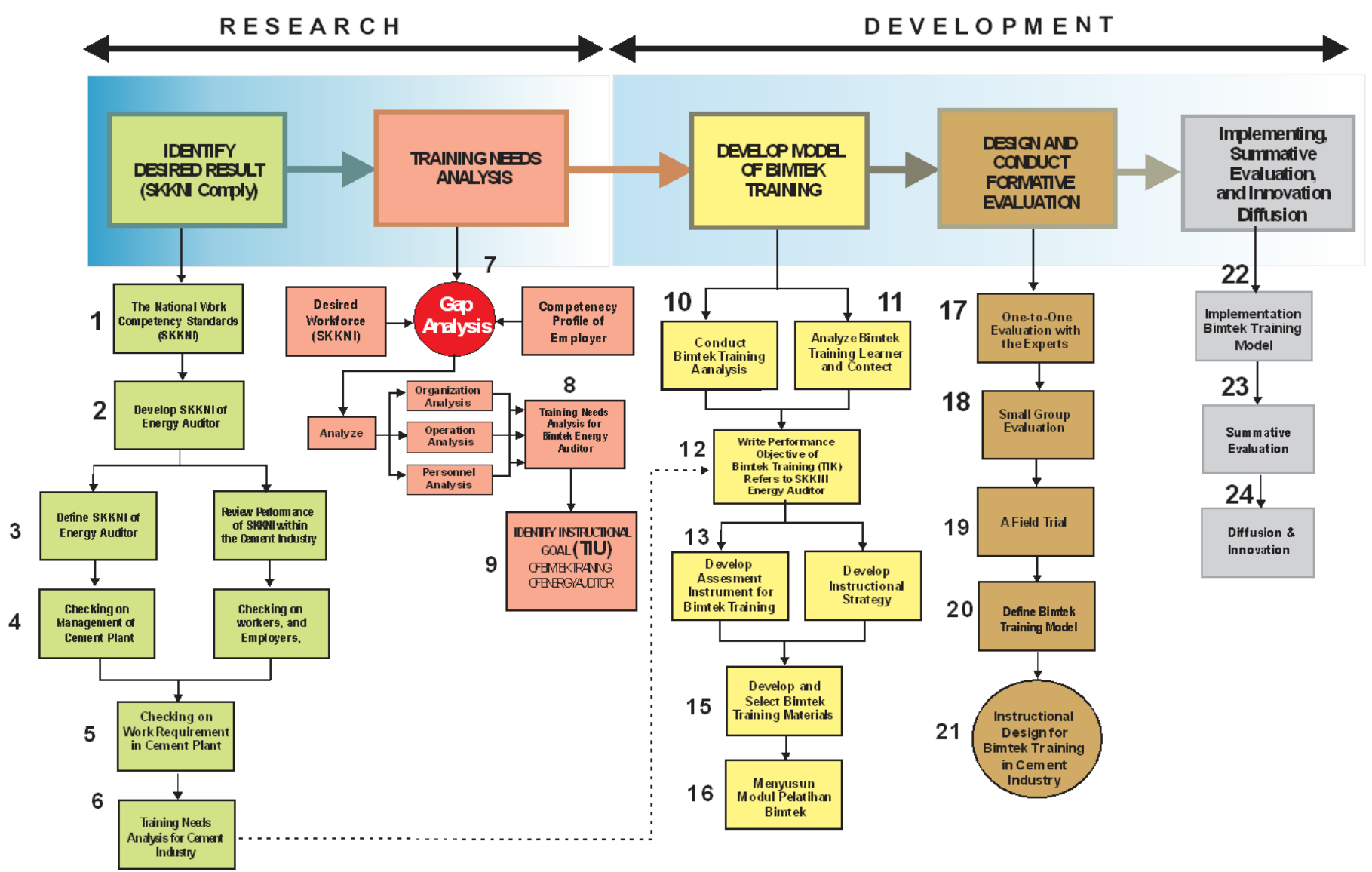

Fig. 4 Process of training model development of Technical Guidance Training of Auditor energy in cement industry

\section{RESULTS AND DISCUSSION}

Before implementing Technical Guidance Training for Energy Auditor, Training Institutions perform the following steps:

\section{A. Identifying training needs (Training Needs Analysis)}

Identification of training needs as stated by Rossett (2009), Hariyo (2013) and Christensen (2016) is a process of collecting data in order to identify areas or any factors that need to be repaired or enhanced through training. Identification of training needs can be done on a macro and/or micro. In General, identification of training needs carried out by training institutions is micro, namely the identification process to find out the gaps or "gap" competence possessed by labor force/potential participants with market needs work or the requirements of the position.

Identification of training needs carried out by way of comparing the real condition of potential attendees with a must-have competence to execute a particular job. The identification can be done by approach: (1) on the level of the industry, to obtain performance information from each section/Department that can affect performance, goals and business plan of the Organization as a whole, so that it can be determined the training needs to become a priority scale; (2) on the level of Office, to obtain task information and details of the duties of a position well to the time now nor likely in the future, then identify the relationship or correlation between tasks and information from the Office of the relevant; (3) at the Individual level, the identification of training needs at individual level are conducted to analyze the level of knowledge, skills and attitudes that are owned by labor or the current participants compared to the level required (gap analysis), so it can be determined what competencies need to be added against a labor or participants. The results of the identification of training needs, should not always responded to the needs of training, but it can also generate a response not only such training guidance and consultation, re-design office, and others.

\section{B. Competency-based training (CBT) programmes devised (CBT)}

CBT Program drawn up based on the identification of training needs. If the results of the identification of training needs has been available standard competencies of good SKKNI, an international standard or a specific standard, then a training program organized by the competence standards. However, if the standard of competencies is not available then the training program must be compiled based on the results of the identification of training needs. In the case of Technical Guidance Training Energy Auditor training, identifying training needs (Training Needs Analysis) based on Regulation of the Minister of Manpower and Transmigration No. 8 year 2014 is the first step in the 
development of a training model of Technical Guidance Training of energy Auditor. Identification of training needs carried out by the training institutions in the cement industry is micro, namely the identification process to find out the gaps or "gap" the competence that is owned by the labor force with the requirements of the position. Program Technical Guidance Training the Auditor prepared based on the results of the identification of training needs, then a training program organized by the national standard of Competence Workplace Indonesia (SKKNI) field energy audits in the cement industry as desired workforce performance If referring to model Human Performance Technology (HPT). The chart in Fig. 5 shows the flow diagram of Technical Guidance Training Energy Auditor training.

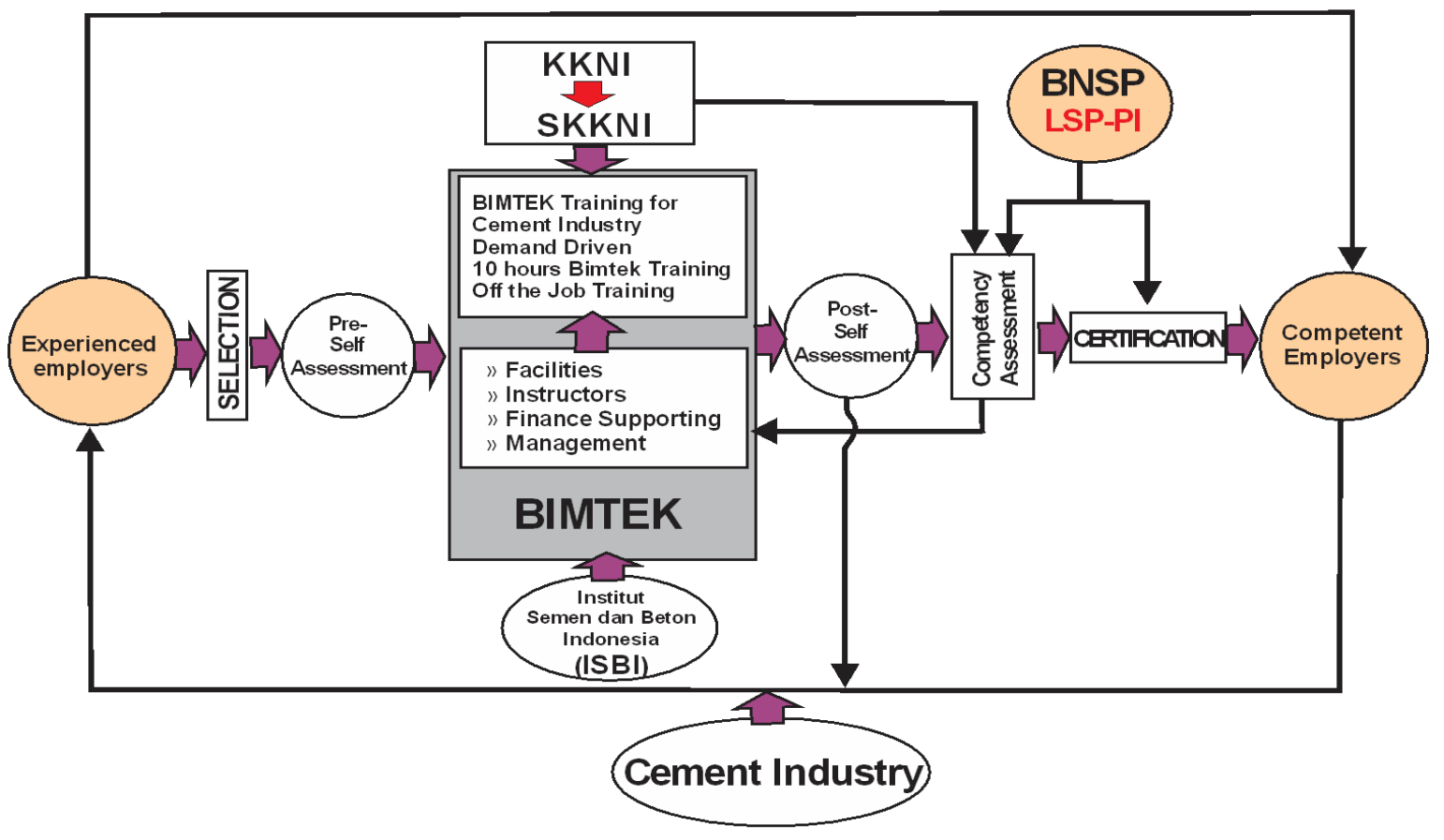

Fig. 5 Flowchart Technical Guidance Training Energy Auditor training program

Training programme drawn up comprising: (1) Title/name of the training programs that describe/show the name of the training program will be implemented. (2) The purpose of describing generally the results of training that will be achieved by the participants. (3) The competencies that will be taken by participants poured in units of competence. (4) The estimated length of time required to complete the training process. Determination of the training time is not absolute/absolute must follow by each of the participants. (5) Requirements of the trainees is a requirement for a minimum qualifying trainee, can consist of: education, age/age, gender. (6) Curriculum and syllabus in the form details and descriptions of the units of competency that will be reached by the participants. Curriculum and syllabus describe: (a) the Unit of competency will be pursued; (b) Elements of competence; (c) criteria of performance to be achieved; (d) Performance Indicators; (e) Science related; (f) Practices necessary to achieve performance; $(\mathrm{g})$ working Attitude is required; (h) the estimated time required for each element of competence. (7) The list of ingredients and equipment that itemize the needs, the number and technical specifications of materials, tools, the necessary machinery for the implementation of the training.

\section{Recruitment and Selection}

Recruitment and selection as stated by Hugh Guthrie, National Center for Vocational Educational Research, Australia (2009), Instructional Design Dick \& Carey/MPI Model (Suparman, 2014) and on Regulation of the Minister of Manpower and Transmigration No. 8 year 2014, are the initial screening process to get candidates that qualify trainees normative. The application of the test material and type in the selection process depends on the training program will be followed. Overall recruitment and selection process can be outlined as follows: (1) Disseminating information on training programs to be implemented as well as its requirements; (2) Perform the registration of potential participants; (3) Prepare a list of potential participants the recapitulation; (4) assign the selection method will be used in accordance with the requirements that have been set. The selection can be done by any one or combination of the following methods as stated by Hugh Guthrie, National Center for Vocational Educational Research, Australia (2009), and Regulation of the Minister of Manpower and Transmigration No. 8 year 2014: (a) a written Test; (b) Interview; (c) Recognition of Current Competency (RCC); d. Recognition Prior Learning (RPL) outcomes (formal, non 
formal or work experience); (5) Perform selection against potential participants.

The purpose of the selection is done to select potential participants in accordance with the specified requirements, and to know the conditions (knowledge, skills) prospective participants. Data/information from the second of these goals is used as a basic training in initiating, setting out the results of the selection, announced the results of the selection, prepare a list of the participants has been declared admissible, and create complete data participants.

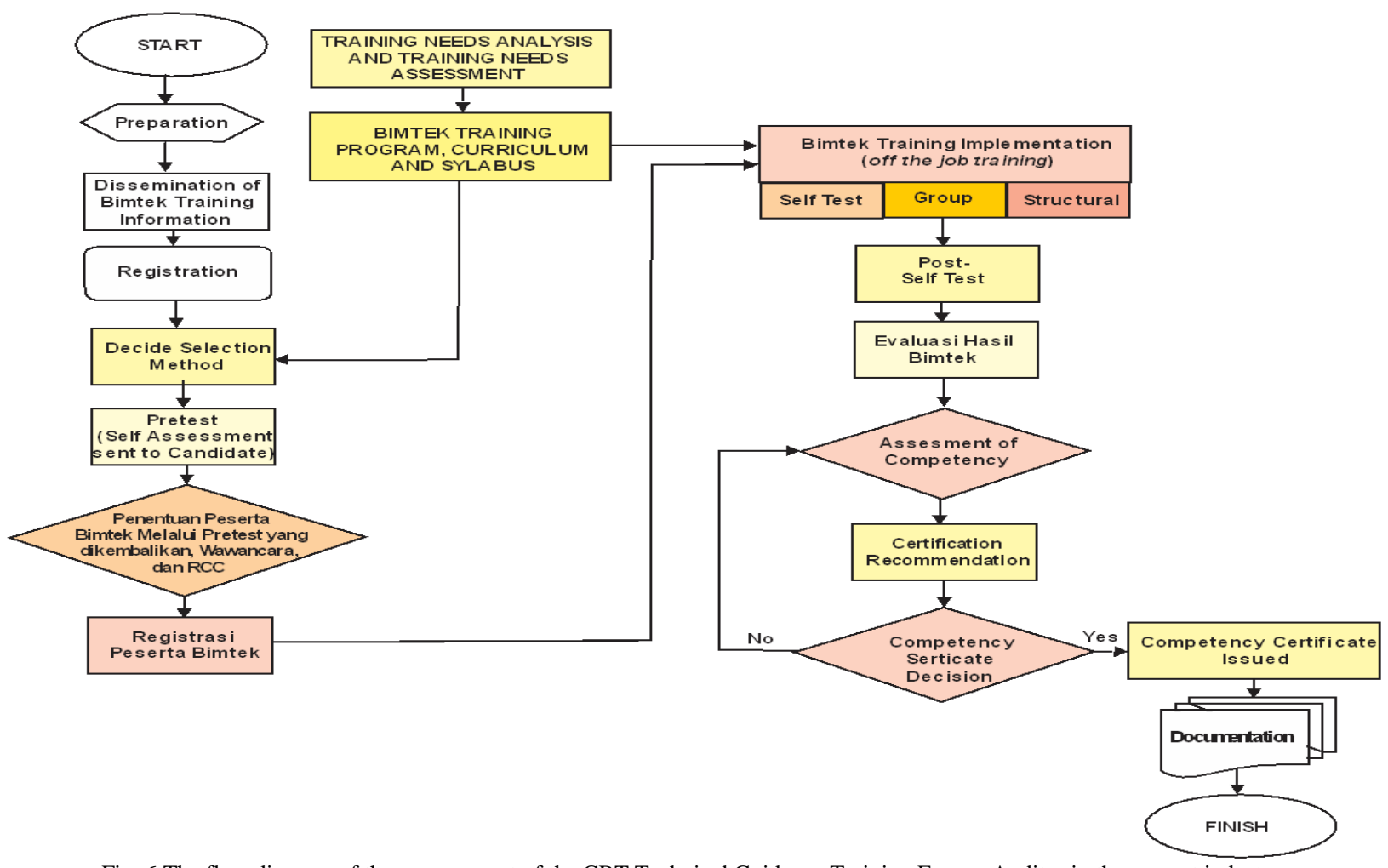

Fig. 6 The flow diagram of the arrangement of the CBT Technical Guidance Training Energy Auditor in the cement industry

\section{Putting Together a Training Plan}

Training plan is a planning document stages training arranged by an analysis of the contents of the training material as a whole. Training plans are used as a reference for coaches to facilitate personnel and choosing the right training method for trainees in accordance with the training material that is each trainee. Minimal training plan contains objectives, training methods and techniques used for each training materials, tools and media training needed for any training material and type of evaluation/assessment will be used.

\section{E. Prepare Human Resources}

1. Training event was preceded by the publication of the letter a. training event by the head of the institution where the training decision letter contains the name of the vocational/sub/vocational training program, the name of the person in charge, the name of the technical implementers, and the name of the trainee; and $b$. the determination of the place of On the Job Training (OJT) at the company, to be integrated with the program of training in training institutions.

2. Qualification Requirement: (1) Trainer competencies methodology and technical competence; (2) Gets the assignment of head of training institutions through the letter assignment; (3) can consist of instructors, supervisor, experts, or other term which is equivalent to it. Training institutions can bring/harness energy coaches from outside such as industry/company in accordance with the required criteria and requirements as mentioned above.

3. Trainer tasks are as follows: (a) Helps participants in planning the training process; (b) Guide participants through training tasks described in training; (c) helps to understand the concept and answer questions participants; (d) Help find the source of the additional information required trainee; (e) Organizes learning activities group if needed; (f) bring in an expert from the workplace if necessary. (g) Test/observe and collect evidence and make the training progress notes for each trainee; (h) Evaluating achievement of the competencies of participants per individual.

4. The role of personnel trainers are: (a) As a speaker, over matter theory and be able to demonstrate the material practices; (b) as a facilitator, capable of bridging the gap between participants and training materials; (c) as a supervisor, was able to help participants develop the learning plans of individuals or groups, encourage critical thinking ways and the ability to solve problems, 
and to motivate the trainees individually; (d) As assessors, make decisions about the RCC/RPL, assessing the competency of individual product according to the criteria and standards set forth, as well as documenting the results of the assessment of each of the participants; (e) As a mechanism, focusing more on the training process and capable of moving the training process. In the process of training, personnel trainer should be able to combine the roles according to the conditions and circumstances that occurred.

5. Trainees are subject to training, and have been following the process of recruitment and selection. Setting up training facilities that need to be prepared: (1) The equipment needed in the framework of the attainment of competencies as defined in the curriculum of training such as: machine, hand tools, equipment and other supporting facilities as well as safety tools; (2) Training materials should be available in sufficient amount and adjusted with the goal of competence that will be pursued and consists of training materials for theory and/or to practice; (3) Training should be available in accordance with the required and consists of classroom, workshop/place of practice, or demonstration along with its furnishings; (4) Modules or training material is the material/learning resources arranged by competency standards work (book, workbook and textbook assessment); (5) Reference books relevant to achieve competence, can be either a text book, manual book, Standard operating procedures, and other related references.

\section{F. Scheduling Training}

Training schedule drawn up by the training providers in each training institutes and is coordinated with the coach. The schedule was used as a handle for energy coaches, organizers, and participants to know the stages during exercise to take place in accordance with the exercise program.

\section{G. Administration Training}

Administration should be prepared, among others: list of present participants, the list of present labor coach, receipt supplies participants, conduct training, training certificate, and assessment forms /assessment.

\section{CONCLUSIONS}

Training Needs Assessment (TNA) or training needs analysis is a move made after specified identify desired result. and before doing any training and are part of integrated designing training to obtain a comprehensive overview of the material, the allocation of time, and learning strategies that should be applied in the Organization of training in order to be useful for training participants. From this analysis will note any relevant training for an organization at present and also in the future. The Organization cannot determine the training for granted without first analyzing the needs and goals of what you want to accomplish. Needs assessment is a road map to achieve the organization goal(s).

The training program aims to develop human resource competence (Competency-based Training), need the structure of curriculum and syllabus-based competencies are often termed as competency-based Curriculum. By using this approach, the Training unit of the CBT under Department of Industry and Department of Labor and Transmigration will be able to ensure competence of anything required by the company/units under it, how to measure the achievement of competencies trained, and what indicators are applied to find out if the apparatus has mastered a given competency.

Competency-based training curriculum design means using competency profiles as a basis for conducting needs analysis training, the result is a set success profile of each unit's next used to determine the syllabus and curriculum of the training will be arranged. In a further description, the author tried to be a bit elaborate on things related to the Organization of education and training with operates on discussion of instructional design training. The methods used in this research is the Research and Development, where research in the research starting in $1^{\text {st }}$ stage with identify desired result which consists of 6 small steps: (1) Development of the cement industry competency map; (2) Develop a draft Indonesia standard of Competence Workplace (RSKKNI) of Energy Auditors; (3) RSKKNI established through the Convention; (4) Department of Labor and Transmigration set SKKNI Energy Auditor; (5) Certification of Energy Auditor Scheme was devised; and (6) Material Test of Competence (MUK) of auditors in the cement industry energy-specified for the purposes of certification of competence Energy Auditor. The next stage in the Research in this study is a competency-based training needs Analysis that consists of: (1) analysis of the gap between the workforce to be desired in this SKKNI Energy Auditor competency profile of the participants training, and (2) training needs analysis is analyzing the gap between the desired result (SKKNI comply) and the energy auditor competency profiles exist through: (a) Performance analysis; (b) Analysis of the environment (Environment Analysis); (c) An analysis of trainee (learner analysis); and (d) Needs Analysis. The third step as the final step in this phase is a common Instructional goal setting (refer to TIU).

\section{REFERENCES}

Christensen, Brett D. (2016). Needs Assessment or Needs Analysis?. Workplace Performance Consulting. Posted on May 26, 2016.

Hariyo. (2013). Training Needs Assessment and Training Strategy. www. wwfnepal.org/publications.

Hugh Guthrie, National Center for Vocational Educational Research, (2009). Competence and Competencybased training: What the literature says. Commonwealth of Australia.

Regulation of the Minister of Manpower and Transmigration No. 8 year 2014 on Competency-Based Training Implementation Guidelines. 
Rossett, Allison. (2009). First Things Fast, 2nd Edition, A Handbook for Performance Analysis, 229, Pfeiffer.

Suparman, Atwi. (2014). Desain Instruksional Modern, $4^{\text {th }}$ Edition. Jakarta: Erlangga.

Watkins, R., Meiers, M.W., and Visser, Y.L. (2012). A guide to assessing needs: Essential tools for collecting information, making decisions and achieving development results. Washington, DC: The World Bank. 